\title{
Pengukuran Kontribusi Komponen Teknologi pada Kapal MM Menggunakan Metode Kombinasi Teknometrik dan Analytical Hierarchy Process (AHP)
}

\author{
Muhammad Nur Safrudin ${ }^{1}$, Udisubakti Ciptomulyono ${ }^{2}$, Ferdy Hendarto Susilo ${ }^{3}$ \\ 1,3 Sekolah Staf Dan Komando Angkatan Laut, ${ }^{2}$ Institut Teknologi Sepuluh Nopember \\ ${ }^{1}$ nursafrudin99@gmail.com, ${ }^{2}$ udisubakti@gmail.com, ${ }^{3}$ kkmmandau@gmail.com
}

DOI: https://doi.org/10.21107/rekayasa.v13i1.5881

\section{ABSTRAK}

Kesiapan tempur kapal perang sangat dipengaruhi oleh komponen teknologi di dalamnya. Komponen teknologi terdiri dari technoware, humanware, infoware, dan orgaware. Kapal MM merupakan satu kapal perang TNI-AL yang sudah berusia di atas 40 tahun. Sebuah pengembangan teknologi perlu dilakukan untuk mengembalikan kemampuan tempurnya. Sebuah penelitian perlu dilakukan untuk memetakan kondisi komponen teknologi saat ini. Penelitian ini bertujuan untuk mengukur tingkat kecanggihan masing-masing komponen teknologi, kontribusi gabungan, dan menentukan prioritas pengembangannya. Metode yang digunakan dalam penelitian ini adalah kombinasi teknometrik dan Analytical Hierarchy Process (AHP). Teknomterik digunakan untuk mengukur kontribusi individual dan Technology Contribution Coefficient (TCC) berdasarkan komponen technoware, humanware, inforware dan orgaware. AHP digunakan untuk menentukan intensitas kontribusi dan bobot kriteria dan sub-kriteria komponen teknologi. Hasil pengukuran kontribusi individual adalah technoware 0,33 , humanware 0,57 , infoware 0,59 , orgaware 0,64 dan TCC adalah 0,48 . Nilai gap dari kontribusi adalah tecnoware 0,67 , humanware 0,43 , infoware 0,41 , dan orgaware 0,36 . Berdasarkan nilai TCC, kapal kelas MM masuk dalam tingkat teknologi semi modern dan klasifikasi cukup baik. Berdasarkan dari nilai gap komponen teknologi maka disarankan komponen technoware menjadi prioritas utama dalam pengembangan teknologi di kapal MM.

Kata Kunci : Humanware, Infoware, Orgaware, Technoware, TCC

\section{PENDAHULUAN}

Tugas Tentara Nasional Indonesia Angkatan Laut (TNI-AL) seperti yang tertuang dalam UndangUndang TNI No. 34 tahun 2004 adalah melaksanakan tugas TNI matra laut di bidang pertahanan, penegak hukum dan keamanan di laut yuridiksi nasional sesuai dengan ketentuan hukum nasional dan internasional, melaksanakan tugas diplomasi AL untuk mendukung kebijakan politik luar negeri yang ditetapkan oleh pemerintah, melaksanakan tugas TNI dalam pembangunan dan pengembangan kekuatan matra laut dan melaksanakan pemberdayaan wilayah pertahanan laut (Undang-Undang TNI No.34, 2004).

TNI- AL dalam menjalankan tugasnya didukung dengan Sistem Senjata Armada Terpadu (SSAT) yang salah satu unsur di dalamnya adalah Kapal Perang Republik Indonesia (KRI). TNI-AL hingga saat ini memiliki berbagai kelas dan type kapal perang untuk menjaga keamanan perairan Indonesai. Kapal perang merupakan alutsista TNI$\mathrm{AL}$ yang didalamnya tersusun atas gabungan beberapa teknologi, yaitu teknologi permesinan, persenjataan, navigasi, dan komunikasi. Sehingga kesiapan tempur kapal perang sangat tergantung dari kesiapan dan kondisi teknologi yang dimiliki.

Kapal MM merupakan salah satunya adalah kapal perang yang dimiliki TNI-AL yang masih aktif dalam menjalankan tugas keangkatan lautan. Seiring dengan pertambahan usia pakai, kemampuan

\section{Article History:}

Received: August, 28 ${ }^{\text {th }}$ 2019; Accepted: January, $12^{\text {th }} 2020$ ISSN: 2502-5325 (Online) Terakreditasi Peringkat 3 oleh Kementerian Riset, Teknologi dan Pendidikan Tinggi (ARJUNA), berdasarkan Keputusan Direktur Jenderal Penguatan Riset dan Pengembangan No: 23/E/KPT/2019 tanggal 8 Agustus 2019 kapal perang ini semakin menurun. Baik kemampuan persenjataan maupun manuver. Faktor penyebab penurunan performa ini adalah teknologi. Sehingga dibutuhkan langkah nyata untuk meningkatkan kemampuan tempur kapal perang MM dari sektor teknologi.

Teknologi merupakan salah satu kunci dalam tercapainya produktivitas sebuah organisasi. Menurut Ahmad, (2014) teknologi mencakup peralatan yang digunakan baik untuk produksi, komunikasi, informasi, informasi atau kontrol. Teknologi merupakan faktor yang mendominasi terbentuknya daya saing perusahaan sehingga diperlukan wawasan yang cermat agar perusahaan dapat berkembang (Gudanowska, 2017). Kapal perang juga dapat dianalogikan sebuah perusahaan. Hanya saja produk output nya adalah kemampuan bermanuver dan bertempur. Menurut UNESCAP (1988) dalam Yanthi, E.R, 2018 menyatakan bahwa teknologi terdiri dari technoware yang menyangkut peralatan fisik, humanware merupakan pengguna technoware, Infoware merupakan dokumen informasi, dan orgaware merupakan teknologi yang melekat pada organisasi.

Dalam rangka meningkatkan kemampuan tempur Kapal MM, perlu diambil langkah-langkah manajemen bidang teknologi secara tepat. Menurut Hamid et.al (2012) terdapat 8 (delapan) prinsipprinsip dalam manajemen teknologi yaitu technology development, technology improvement, technology leadership, technology pathership, technology pioneering, technology integration, technol-

\section{Cite this as:}

Safrudin, M.N., Ciptomulyono, U., \& Susilo, F.H. (2020). Pengukuran Kontribusi Komponen Teknologi pada Kapal MM Menggunakan Metode Kombinasi Teknometrik dan Analytical Hierarchy Process (AHP). Rekayasa, 13(1), 31-37. doi: https:// doi.org/10.21107/rekayasa.v13i1.5881 
ogy value, dan technology standart. Dari beberapa prinsip manajemen teknologi tersebut, yang paling memungkinkan dilaksanakan di Kapal MM adalah technology development. Gudanowska ( 2017) menyatakan bahwa kegiatan menajemen teknologi tidak terbatas pada pengelolaan seperangkat teknologi tertentu, namun juga melakukan strategi pengembangan dalam aspek sumber daya yang ada dan teknologi exisisting yang digunakan.

Berdasarkan latar belakang tersebut, sebuah penelitian perlu dilaksanakan dalam rangka untuk mengetahui status kondisi komponen teknologi (technoware, humanware, infoware, dan orgaware). Tujuan dari penelitian ini adalah untuk melakukan pengukuran kontribusi individual, kontribusi gabungan, dan menentukan prioritas pengembangan dari komponen teknologi di Kapal MM. Penelitian ini perlu dilaksanakan sebagai masukan dan informasi bagi TNI-AL dalam menyusun perencanaan, perbaikan dan pengembangan komponen teknologi di Kapal MM secara tepat di masa mendatang. Penelitian terkait manajemen teknolog telah banyak dilaksanakan antara lain penelitian oleh Coccia M. 2018, Daim, T.U et.al, 2018, Foden J, 2010, dan Wang CC.et.al , 2016. Sedangkan penelitian yang akan dilaksanakan kali ini akan menggunakan pendekatan teknometrik yang dikombinasikan dengan AHP.

Teknometrik merupakan model yang dapat digunakan dalam menentukan aspek-aspek pengukuran komponen teknologi (Nazarudin, 2008). Sedangkan AHP digunakan untuk pembobotan pada kriteria dan sub-kriteria komponen teknologi dan untuk menentukan skala prioritas (Saaty.L., 1993). Teknometrik telah banyak digunakan untuk melaksanakan pengukuran komponen teknologi antara lain penelitian oleh (Setiawan J, et.al. 2015 Pujianto T, et.al, 2017, Virliantarto, N., et.al 2017, Irianto, B.G., et.al 2015, Susihono, W. 2012). Sedangkan beberapa penelitian yang menggunakan AHP telah dilaksanakan antara lain oleh (Anis $Y$ et.al 2015, Cahyono DECW. 2105, dan Darmanto E. 2014).

\section{METODE PENELITIAN}

\section{Tempat dan Waktu Penelitian}

Kegiatan penelitian terdiri dari pengambilan data dan pengolahan data. Pengambilan data dilaksanakan pada tanggal 27 - 28 Juni 2019 di Kapal MM yang berada di pangkalan TNI-AL Surabaya. Sedangkan pengolahan dan analisis data dilakukan pada tanggal 1 Juli 2019 sampai dengan 16 Agustus 2019.

\section{Teknik pengumpulan Data \\ Jenis Data}

Data yang yang digunakan dalam penelitian ini adalah data primer dan sekunder. Masing-masing data dikumpulkan dengan metode yang berbeda, yaitu :

\section{Data Primer}

Data primer merupakan data yang diperoleh secara langsung berdasarkan hasil pengamatan langsung, wawancara, dan kuesioner terhadap obyek penelitian. Data primer dalam penelitian in antara lain :

1) Penentuan kriteria dan sub-kriteria komponen teknologi

2) Penentuan indikator penilaian komponen teknologi.

3) Penentuan estimasi tingkat sofistikasi.

4) Penentuan nilai State of The Art (SOTA).

5) Penilaian perbandingan berpasangan komponen teknologi.

\section{Data Sekunder}

Data sekunder merupakan data yang diperoleh tidak secara tidak langsung terhadap obyek penelitian. Data ini diperoleh melalui studi literatur berupa dokumen-dokumen yang ada di obyek penelitian. Data tersebut meliputi :

1. Struktur organisasi dari obyek penelitian.

2. Sejarah singkat dari obyek penelitian.

\section{Instrumen Penelitian}

Beberapa instrumen yang digunakan untuk pengumpulan data dalam penelitian ini adalah sebagai berikut :

a. Instrumen untuk mengukur tingkat kecanggihan (sofistikasi) komponen teknologi. Instrumen ini berisi tentang kriteria-kriteria dan sub-sub kriteria pengukuran dan indikator yang digunakan sebagai dasar responden dalam pemberian nilai.

b. Instrumen untuk mengukur kemutakhiran teknologi. Instrument ini juga dibuat untuk memperoleh data-data nilai yang akan digunakan utk pengukuran State of Art (SOTA).

c. Instrumen untuk menentukan penilaian dari perbandingan berpasangan pada metode Analytical Hierarchy Process (AHP) yang akan digunakan sebagai dasar penentuan skala prioritas dan bobot kriteria dan sub-kriteria pada komponen teknologi.

\section{Teknik Pengolahan Data}

Setelah data yang diperlukan telah terkumpul, maka langkah selanjutnya adalah melaksanakan pengolahan dengan menggunakan metode teknometrik. Langkah-langkah penggunaan metode teknometrik adalah sebagai berikut:

\section{Pengamatan Komponen Teknologi}

Dalam penelitian ini telah ditentukan kriteria dan sub-kriteria dan dapat dilihat di Tabel 1.

\section{Estimasi Tingkat Sofistikasi}

Untuk menentukan tingkat sofistikasi komponen teknologi dapat dilakukan dengan menentukan nilai batas atas (upper limit) dan bawah (lower limit) tingkat kecanggihan komponen teknologi dengan uji kualitatif skoring 1-9. Untuk menentukan tingkat sofistikasi fasilitas transformasi, dapat dilakukan dengan langkah-langkah sebagai berikut :

a. Melakukan penelitian kualitatif untuk keempat komponen teknologi dan mengumpulkan semua informasi teknologi yang relevan.

b. Mengidentifikasikan semua item utama masing-masing komponen teknologi, berdasarkan penelitian kualitatif yang dilakukan.

c. Menentukan batas atas dan batas bawah tingkat sofistikasi masing-masing komponen teknologi pada fasilitas transformasi yang diamati. 
Tabel 1. Kriteria dan Sub-kriteria Komponen Teknologi Kapal MM

\begin{tabular}{|c|c|c|}
\hline $\begin{array}{l}\text { KOMPONEN } \\
\text { TEKNOLOGI }\end{array}$ & KRITERIA & SUB-KRITERIA \\
\hline \multirow{6}{*}{ Technoware } & & Sistem Pendorong \\
\hline & Platform & Sistem Bantu \\
\hline & & Sistem Keselamatan \\
\hline & & Sistem Komunikasi \\
\hline & Sewaco & Sistem Senjata \\
\hline & & Sistem Navigasi \\
\hline \multirow{6}{*}{ Humanware } & Contact & Perwira divisi mesin \\
\hline & Humanware & Perwira divisi elektronika \\
\hline & & Operator Platform \\
\hline & & Operator Sewaco \\
\hline & Support & Kepala Departemen mesin \\
\hline & Humanware & Kapala Departemen Elektronika \& Senjata \\
\hline \multirow{8}{*}{ Infoware } & Infoware Terkait & Infoware Pengoperasian teknoware (IPT) \\
\hline & Technoware & $\begin{array}{l}\text { Infoware perbaikan performansi Tech- } \\
\text { noware (IPPT) }\end{array}$ \\
\hline & & Infoware perawatan technoware (IPT2) \\
\hline & & Infoware atribut technoware (IAT) \\
\hline & Infoware Terkait & Infoware Atribut humanware (IAH) \\
\hline & Humanware & Infoware pendukung humanware (IPH) \\
\hline & Infoware Terkait & Infoware atribut orgaware (IAO) \\
\hline & Orgaware & Infoware perbaikan orgaware (IPO) \\
\hline \multirow{4}{*}{ Orgaware } & Organisasi kerja & \\
\hline & Fasilitas Kerja & - \\
\hline & Evaluasi kerja & \\
\hline & Modifikasi Kerja & \\
\hline
\end{tabular}

\section{Penilaian Kecanggihan Mutakhir}

Penilaian kecanggihan mutakhir atau SOTA komponen teknologi diawali dengan penentuan indikator penilaian. Masing-masing indikator diberikan skor (1-10). Selanjutnya berdasarkan hasil kuesioner yang diperoleh, maka nilai SOTA masing-masing komponen teknologi dengan persamaan sebagai berikut:

Kecanggihan mutakhir technoware $\left(\mathrm{ST}_{\mathrm{i}}\right)$

$\mathrm{ST}_{\mathrm{i}}=\frac{1}{10}\left[\frac{\sum_{k=1}^{k_{t}} t_{i k}}{k_{t}}\right]$

Kecanggihan mutakhir humanware $\left(\mathrm{SH}_{\mathrm{j}}\right)$

$\mathrm{SH}_{\mathrm{j}}=\frac{1}{10}\left[\frac{\sum_{l=1}^{l_{h}} h_{j i}}{l_{h}}\right]$

Kecanggihan mutakhir Infoware (SI)

$\mathrm{ST}_{\mathrm{i}}=\frac{1}{10}\left[\frac{\sum_{m=1}^{m_{t}} f_{m i}}{m_{t}}\right]$

Kecanggihan mutakhir Orgaware (SO)

$\mathrm{ST}_{i}=\frac{1}{10}\left[\frac{\sum_{n=1}^{n_{0}} o_{n}}{n_{t}}\right]$

Keterangan :

$\mathrm{t}_{\text {ik }}=$ Skor kriteria ke-k untuk technoware item i

$\mathrm{h}_{\mathrm{ji}}=$ Skor kriteria ke-I untuk humanware kategori j

$f_{i m}=$ Skor kriteria ke-m untuk infoware

$\mathrm{O}_{n}=$ Skor kriteria ke-n untuk orgaware

Pembagian dengan 10 pada setiap persamaan digunakan untuk menormalisasi rating menjadi 0 dan 1. Jika ada alas an bahwa sejumlah kriteria mempunyai bobot yang lebih penting dari lainnya, maka persamaan - persamaan di atas dapat dimodifikasi menjadi :

$\mathrm{ST}_{\mathrm{j}}=\frac{1}{10}\left[\frac{\sum W_{k} t_{i k}}{\sum W_{k}}\right]$

Dengan $\mathrm{w}_{\mathrm{k}}$ adalah bobot untuk $\mathrm{k}$ dan $\mathrm{S}_{\mathrm{wK}}=1$

\section{Perhitungan Kontribusi komponen teknologi.}

Berdasarkan batas-batas tingkat sofistikasi yang telah ditentukan dan rating kecanggihan muthakir, kontribusi komponen (compenent contribution) dapat dihitung dengan persamaan-persamaan di bawah ini :

$$
\begin{aligned}
& \mathrm{T}_{\mathrm{i}}=1 / 9\left[L_{T i}+S_{T i}\left(U_{T i}-L_{T i}\right)\right] . \\
& H j=\frac{1}{9}\left[L_{H j}+S_{H j}\left(U_{H j}-L_{H j}\right] \ldots \ldots .\right. \\
& I=\frac{1}{9}\left[L_{I}+S_{I}\left(U_{I}-L_{I}\right)\right] \\
& O=\frac{1}{9}\left[L_{O}+\text { So(Uo-Lo) }\right]
\end{aligned}
$$

Keterangan :

$\mathrm{Ti}=$ kontribusi masing-masing item $\mathrm{i}$ dari technoware

$\mathrm{Hj}=$ kontribusi masing-masing item $\mathrm{j}$ dari humanware

= kontribusi infoware

$\mathrm{O}=$ kontribusi orgaware

$\mathrm{U}=$ batas atas

$\mathrm{L}=$ batas bawah

\section{Penilaian Intensitas Kontribusi Komponen}

Untuk mengestimasi intensitas kontribusi komponen dapat dilakukan dengan menggunakan pendekatan matriks perbandingan berpasangan. Pada penelitian ini digunakan metode AHP dan dalam penyelesaiannya menggunakan program expert choice- 11.

\section{Perhitungan TCC}

Technology Contribution Coeffisient (TCC) dalam suatu fasilitas transformasi didefinisikan sebagai berikut :

$T C C=T^{b t} \times H^{b h} \times\left.\right|^{b i} \times O^{b o}$

Keterangan :

$\mathrm{T}=$ Kontribusi rekayasa terhadap kontribusi teknoware

$\mathrm{H}=$ Kontribusi humanware

1 = Kontribusi infoware

$\mathrm{O}=$ Kontribusi orgaware

$\mathrm{b}=$ Intensitas kontribusi

\section{HASIL DAN PEMBAHASAN}

\section{Perhitungan Derajat Kecanggihan Tech- noware}

Berdasarkan Tabel 2, nilai batas bawah (LT) adalah 1 yang berarti peralatan dan fasilitas ada yang masih menggunakan sistem manual. Nilai batas atas (UT) adalah 6 yang berarti fasilitas dan peralatan sudah ada yang menggunakan komputerisasi. Nilai SOTA tertinggi adalah pada sistem keselamatan sebesar 0,75 yang berarti memiliki derajat kemutakhiran yang paling tinggi. SOTA terendah adalah sistem senjata yaitu sebesar 0,22 . Kontribusi terbesar pada kriteria platform adalah pada 
34 | Safrudin, M.N., dkk., Pengukuran Kontribusi Komponen Teknologi pada Kapal MM...

Tabel 2. Pengukuran Nilai Komponen Technoware

\begin{tabular}{|c|c|c|c|c|c|c|c|c|}
\hline \multirow{2}{*}{ TECHNOWARE } & \multirow{2}{*}{ SUB-SISTEM } & \multicolumn{7}{|c|}{ KAPAL MM } \\
\hline & & UT & LT & $\Delta$ & SOTA & KONTRIBUSI & вовот & RATING TERBOBOT \\
\hline \multirow{3}{*}{ Platform } & Sistem Pendorong & 6 & 1 & 5 & 0,46 & 0,37 & 0,33 & \\
\hline & Sistem Bantu & 6 & 1 & 5 & 0,5 & 0,39 & 0,33 & 0,40 \\
\hline & Sistem Keselamatan & 5 & 1 & 4 & 0,75 & 0,44 & 0,33 & \\
\hline \multirow{3}{*}{ Sewaco } & Sistem Komunikasi & 3 & 2 & 1 & 0,25 & 0,25 & 0,33 & \\
\hline & Sistem Senjata & 4 & 1 & 3 & 0,225 & 0,19 & 0,33 & 0,26 \\
\hline & Sistem Navigasi & 4 & 2 & 2 & 0,5 & 0,33 & 0,33 & \\
\hline
\end{tabular}

sistem keselamatan sebesar 0,44 yang artinya memberikan kontribusi terbesar terhadap nilai derajat technoware. Sedangkan pada kriteria Sewaco kontribusi terbesar adalah pada sistem navigasi sebesar 0,5 dan terendah 0,19 pada sistem senjata. Bobot pada sub-kriteria seluruhnya sama 0,3 , hal ini menunjukkan bahwa sub-kriteria sub-kriteria tersebut memiliki tingkat kepentingan yang sama.

Derajat kecanggihan technoware dihitung dengan menjumlahkan hasil kali antara bobot kriteria/ sub-kriteria dengan kontribusi technoware. Hasil perhitungan derajat kecanggihan technoware dapat dilihat pada tabel 3.

Pada Tabel 3, menunjukkan bahwa bobot kriteria Platform dan Sewaco adalah sama besar yaitu 0,50 . Hal ini berarti keduanya memiliki tingkat kepentingan yang sama. Sedangkan nilai derajat kecanggihan technoware/kontribusi technoware adalah 0,33. Hal ini menunjukkan nilai derajat kecanggihan technoware kapal MM adalah tergolong rendah. Hal ini disebabkan peralatan platform dan sewaco teknologinya sudah tertinggal.

Tabel 3. Pengukuran Derajat Kecanggihan Technoware

\begin{tabular}{lccc}
\hline TECHNOWARE & $\begin{array}{c}\text { KOBOT } \\
\text { KRITERIA }\end{array}$ & $\begin{array}{c}\text { RATING } \\
\text { TERBOBOT }\end{array}$ & $\begin{array}{c}\text { DERAJAT } \\
\text { KECANGGIHAN }\end{array}$ \\
Platform & 0,5 & 0,4 & 0,33 \\
Sewaco & 0,5 & 0,26 & \\
\hline
\end{tabular}

Tabel 4. Pengukuran Nilai Komponen Humanware

\begin{tabular}{|c|c|c|c|c|c|c|c|c|}
\hline \multirow{2}{*}{ HUMANWARE } & \multirow{2}{*}{ SUB-SISTEM } & \multicolumn{7}{|c|}{ KAPAL MM } \\
\hline & & UH & LH & $\Delta$ & SOTA & KONTRIBUSI & вовот & RATING TERBOBOT \\
\hline \multirow{4}{*}{ Contact Humanware } & Perwira divisi mesin & 5 & 3 & 2 & 0,88 & 0,53 & 0,28 & \multirow{4}{*}{0,48} \\
\hline & Perwira divisi eka & 5 & 3 & 2 & 0,90 & 0,53 & 0,28 & \\
\hline & Operator Platform & 4 & 3 & 1 & 0,79 & 0,42 & 0,22 & \\
\hline & Operator Sewaco & 4 & 3 & 1 & 0,79 & 0,42 & 0,22 & \\
\hline \multirow{2}{*}{ Support Humanware } & Kadep Sin & 6 & 3 & 3 & 0,83 & 0,61 & 0,50 & \multirow{2}{*}{0,62} \\
\hline & Kadep Eka & 6 & 3 & 3 & 0,88 & 0,63 & 0,50 & \\
\hline
\end{tabular}

Tabel 6. Pengukuran Nilai Komponen Infoware

\begin{tabular}{|c|c|c|c|c|c|c|c|c|}
\hline \multirow{2}{*}{ INFOWARE } & \multirow{2}{*}{ SUB-SISTEM } & \multicolumn{7}{|c|}{ KAPAL MM } \\
\hline & & UI & LI & $\Delta$ & SOTA & KONTRIBUSI & вовот & RATING TERBOBOT \\
\hline Infoware Terkait & IPT & 6 & 3 & 3 & 0,8 & 0,60 & 0,34 & \multirow{4}{*}{0,66} \\
\hline \multirow[t]{3}{*}{ Technware } & IPPT & 7 & 3 & 4 & 1 & 0,78 & 0,26 & \\
\hline & IPT2 & 6 & 3 & 3 & 0,96 & 0,65 & 0,32 & \\
\hline & IAT & 5 & 2 & 3 & 1 & 0,56 & 0,08 & \\
\hline Infoware Terkait & $\mathrm{IAH}$ & 5 & 1 & 4 & 0,7 & 0,42 & 0,56 & \multirow{2}{*}{0,43} \\
\hline Humanware & $\mathrm{IPH}$ & 4 & 2 & 2 & 1 & 0,44 & 0,44 & \\
\hline Infoware Terkait & IAO & 5 & 1 & 4 & 1 & 0,56 & 0,5 & \multirow{2}{*}{0,58} \\
\hline Orgaware & IPO & 6 & 3 & 3 & 0,8 & 0,60 & 0,5 & \\
\hline
\end{tabular}

Perhitungan Tingkat Kecanggihan Humanware Berdasarkan Tabel 4, nilai batas atasnya (UH) adalah 6 yaitu pada sub-sistem Kadep Sin dan Kadep Eka yang artinya memiliki kemampuan melakukan improvisasi. Nilai batas bawah (LH) adalah 3, yang artinya memiliki kemampuann melaksanakan memperbaiki. Nilai SOTA dari humanware secara keseluruhan adalah baik, karena bernilai paling rendah 0,79 . Sedangkan nilai kontribusi tertinggi ada pada kriteria adalah Kadep Eka sebesar 0,63.

Derajat kecanggihan Humanware dihitung dengan menjumlahkan hasil kali antara bobot kriteri/ sub-kriteria dengan kontribusi Humanware. Hasil perhitungan derajat kecanggihan humanware dapat dilihat pada tabel 5 .

Bersarkan Tabel 5, nilai derajat kecanggihan sar 0,57. Hal ini berarti bahwa derajat kecanggihan humanware di Kapal MM sudah cukup baik karena para pada dasarnya tugas pokok para personel pengawak peralatan dan fasilitas adalah sebatas operator.

Tabel 5. Pengukuran Derajat Humanware

\begin{tabular}{cccc}
\hline HUMANWARE & $\begin{array}{c}\text { KAPAL MM } \\
\text { KRITERIA }\end{array}$ & $\begin{array}{c}\text { RATING } \\
\text { TERBOBOT }\end{array}$ & $\begin{array}{c}\text { DERAJAT } \\
\text { KECANGGIHAN }\end{array}$ \\
$\begin{array}{c}\text { Contact } \\
\text { Humanware } \\
\begin{array}{c}\text { Support } \\
\text { Humanware }\end{array}\end{array}$ & 0,39 & 0,48 & 0,57 \\
\hline
\end{tabular}
humanware atau nilai kontribusi individual sebe- 


\section{Gambar 1. Hasil Pengolahan Data Bobot Komponen Teknologi}

\section{Perhitungan Derajat Kecanggihan Infoware}

Berdasarkan Tabel : nilai batas atasnya adalah 7 yaitu pada informasi terkait tecnoware yang dapat digunakan untuk mendukung perbaikan. Nilai batas bawah adalah 1 sebab informasi yang ada hanya mampu digunakan sebagai informasi pengenalan. Nilai SOTA masuk dalam kategori baik, dengan nilai terendah 0,7 dan tertinggi adalah 1.

Berdasarkan Tabel 6, selanjutnya derajat kecanggihan infoware dapat dihitung seperti tampak pada tabel 7 di bawah ini.

Berdasarkan hasil perhitungan pada Tabel 7, nilai derajat kecanggihan infoware adalah 0,59. Hal ini menunjukkan bahwa nilai kecanggihan infoware tergolong cukup baik, namun masih dapat ditingkatkan mendekati ideal 1.

\section{Perhitungan Derajat Kecanggihan Orgaware}

Pada komponen orgaware secara umum memiliki SOTA yang baik karena memiliki nilai berkisar 0,9 sampai dengan 1. Nilai kontribusi tertinggi adalah 0,67 yaitu pada sub-sistem organisasi kerja. Hal ini berarti bahwa organisasi kerja memberikan kontribusi terbesar dalam nilai komponen orgaware. Berdasarkan hasil pembobotan AHP organisasi kerja memiliki bobot tertinggi yaitu 0,33. Hal ini berarti bahwa organisasi memiliki tingkat kepentingan paling tinggi dalam komponen orgaware. Selanjutnya derajat kecanggihan Orgaware dihitung dengan menjumlahkan hasil kali antara bobot kriteri/ sub-kriteria dengan kontribusi Orgaware. Hasil

Tabel 7. Pengukuran Derajat Kecanggihan Infoware

\begin{tabular}{|c|c|c|c|}
\hline & & KAPAL MM & \\
\hline INFOWARE & $\begin{array}{c}\text { BOBOT } \\
\text { KRITERIA }\end{array}$ & $\begin{array}{c}\text { RATING } \\
\text { TERBOBOT }\end{array}$ & $\begin{array}{c}\text { DERAJAT } \\
\text { KECANGGIHAN }\end{array}$ \\
\hline $\begin{array}{c}\text { Infoware Terkait } \\
\text { Technware }\end{array}$ & 0,61 & 0,65 & \\
\hline $\begin{array}{c}\text { Infoware Terkait } \\
\text { Humanware }\end{array}$ & 0,21 & 0,43 & 0,59 \\
\hline $\begin{array}{c}\text { Infoware Terkait } \\
\text { Orgaware }\end{array}$ & 0,18 & 0,58 & \\
\hline
\end{tabular}

perhitungan derajat kecanggihan Orgaware adalah sebagai berikut:

Berdasarkan hasil perhitungan pada Tabel 8, diketahui nilai derajat kecanggihan orgaware adalah 0,64. Nilai tersebut menunjukkan bahwa kecanggihan orgaware di Kapal MM adalah dalam kategori baik, namun masih dapat ditingkatkan mendekati ideal 1.

\section{Penentuan Intensitas Kontribusi Komponen Teknologi}

Pada penelitian ini, intensitas kontribusi komponen ditentukan dengan menggunakan AHP. Penggunaan AHP disini sebatas pada penggunaan matrik perbandinan berpasangan (pairwise comparasion). Selanjutnya matrik tersebut diisi oleh responden/ expert dalam hal ini para perwira yang bertanggung jawab terhadap peralatan dan fasilitas di Kapal MM. Pendapat para expert tersebut selanjutnya diambil nilai rata-rata geometrik dan diolah menggunakan expert choice - 11. Berikut ini hasil pembobotan dari keempat komponen teknologi di Kapal MM.

Berdasarkan Gambar 1, dapat diketahui bobot komponen technoware sebesar 0,335, humanware 0,335, Infoware 0,161, dan orgaware 0,169. Nilai bobot tersebut merupakan nilai intensitas komponen teknologi.

\section{Perhitungan Tecnology Coefisient Contribution (TCC) Kapal MM}

TCC merupakan kontribusi gabungan dari komponen teknologi. Hasil TCC merupakan hasil penjumlahan dari perkalian antara intensitas dan dan kontribusi komponen teknologi pada masingmasing komponen teknologi. Hasil perhitungan TCC Kapal MM dituangkan dalam Tabel 9.

Berdasarkan Tabel 9 dapat dijelaskan bahwa nilai TCC Kapal MM adalah 0,48. Kontribusi tertinggi adalah pada komponen orgaware sebesar 0,64 dan terendah pada komponen technoware sebesar 0,33 .

Tabel 8. Pengukuran Derajat Kecanggihan Komponen Orgaware

\begin{tabular}{|c|c|c|c|c|c|c|c|c|}
\hline \multirow{2}{*}{ SISTEM } & \multirow{2}{*}{ SUB-SISTEM } & \multicolumn{7}{|c|}{ KAPAL MM } \\
\hline & & vo & Lo & $\Delta$ & SOTA & KONTRIBUSI & вовот & DERAJAT KECANGGIHAN \\
\hline \multirow{4}{*}{ Orgaware } & Organisasi kerja & 6 & 2 & 4 & 1 & 0,67 & 0,33 & \multirow{4}{*}{0,64} \\
\hline & Fasilitas Kerja & 6 & 3 & 3 & 0,9 & 0,63 & 0,29 & \\
\hline & Evaluasi kerja & 6 & 2 & 4 & 0,93 & 0,64 & 0,2 & \\
\hline & Modifikasi Kerja & 6 & 2 & 4 & 0,9 & 0,62 & 0,18 & \\
\hline
\end{tabular}


Tabel 9. Hasil Perhitungan TCC Kapal MM

\begin{tabular}{|c|c|c|c|}
\hline KOMPONEN & & KAPAL MM & \\
\hline TEKNOLOGI & $\begin{array}{l}\text { INTENSI- } \\
\text { TAS }\end{array}$ & $\begin{array}{c}\text { KONTRIBUSI KOMPONEN } \\
\text { TEKNOLOGI }\end{array}$ & TCC \\
\hline Technoware & 0,335 & 0,33 & \\
\hline Humanware & 0,335 & 0,57 & 0,48 \\
\hline Infoware & 0,161 & 0,59 & \\
\hline Orgaware & 0,169 & 0,64 & \\
\hline $\begin{array}{l}\text { Inconsistency } \\
\text { Ratio }\end{array}$ & 0,0005 & & \\
\hline
\end{tabular}

Tabel 10. Hasil Perhitungan Gab THIO Kapal MM

\begin{tabular}{lcc}
\hline \multicolumn{1}{c}{ Komponen Teknologi } & $\begin{array}{c}\text { Tingkat } \\
\text { Kecanggihan }\end{array}$ & Gap \\
\hline Technoware & 0,33 & 0,67 \\
Humanware & 0,57 & 0,43 \\
Infoware & 0,59 & 0,41 \\
Orgaware & 0,64 & 0,36 \\
\hline
\end{tabular}

Tabel 11. Penilaian Klasifikasi Kualitatif Selang Kang

\begin{tabular}{cc}
\hline NILAI TCC & TINGKAT KLASIFIKASI \\
\hline $0<\mathrm{TCC} \leq 0,1$ & Sangat Rendah \\
$0,1<\mathrm{TCC} \leq 0,3$ & Rendah \\
$0,3<\mathrm{TCC} \leq 0,5$ & Cukup \\
$0,5<\mathrm{TCC} \leq 0,7$ & Baik \\
$0,7<\mathrm{TCC} \leq 0,9$ & Sangat Baik \\
$0,9<\mathrm{TCC} \leq 1$ & Kecanggian Mutakhir
\end{tabular}

Sumber: Indriartiningsih, 2014. Kecanggian Mutakhir

Tabel 12. Tingkat Teknologi Berdasarkan TCC

\begin{tabular}{cc}
\hline NILAI TCC & TINGKAT KLASIFIKASI \\
\hline $0<\mathrm{TC} \leq 0,1$ & Sangat Rendah \\
$0,1<\mathrm{TCC} \leq 0,3$ & Rendah \\
$0,3<\mathrm{TCC} \leq 0,5$ & Cukup \\
\hline Sumber $:$ Indriartiningsih, 2014.
\end{tabular}

\section{Analisis Nilai Gap Komponen Teknologi}

Niai gap menunjukkan ukuran yang perbaikan yang dibutuhkan pada setiap komponen teknologi berdasarkan pada nilai SOTA yaitu 1. Semakin kecil gap, maka semakin kecil usaha perbaikan/ pengembangan yang dibutuhkan. Kondisi gap pada Kapal MM dapat ditunjukkan pada diagram THIO pada Gambar 2.

Berdasarkan Gambar 2, dapat diketahui bahwa adanya kesenjangan pada nilai THIO di Kapal MM dengan SOTA yang menghasilkan gab. Besarnya gap komponen THIO adalah sebagai berikut pada tabel 10.

Berdasarkan Tabel 10, dapat diketahui nilai peningkatan yang harus dilaksanakan adalah technoware sebesar 0,67, tertinggi kedua pada humanware sebesar 0,43, urutan berikutnya adalah infoware sebesar 0,41, dan terakhir adalah orgaware sebesar 0,36. Berdasarkan gap ini, maka dapat ditentukan prioritas pengembangan komponen teknologi adalah technoware menempati urutan pertama, kedua humanware, ketiga infoware, dan keempat orgaware.

\section{Analisis TCC}

Dalam menganalisa TCC, akan digunakan tabel penilaian klasifikasi selang dan tingkat teknologi TCC. Kedua tabel tersebut adalah tertera pada Tabel 11 dan 12.

\section{PEMETAAN KOMPONEN TEKNOLOGI KAPAL MM}

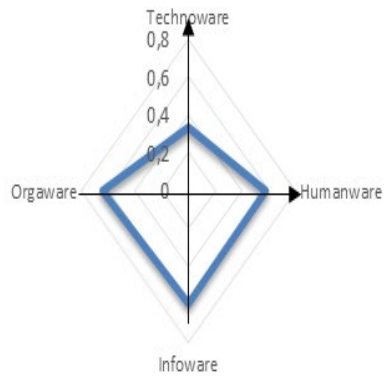

Gambar 2. Grafik THIO di Kapal MM

Berdasarkan hasil perhitungan, TCC Kapal MM adalah 0,48. Maka berdasarkan nilai TCC tersebut, teknologi di Kapal MM masuk dalam klasifikasi cukup dan tingkat teknologi semi modern.

\section{KESIMPULAN DAN SARAN}

\section{Kesimpulan}

Secara umum berdasarkan hasil pengukuran yang dilakukan memberikan kesimpulan sebagai berikut :

a. Hasil pengukuran nilai kontribusi derajat kecanggihan komponen teknologi Kapal MM menunjukkan komponen orgaware memiliki nilai tertinggi 0,64, tertinggi kedua adalah infoware dengan kontribusi 0,59, tertinggi ketiga adalah humanware dengan kontribusi 0,57 , dan yang paling rendah adalah komponen technoware dengan kontribusi 0,33.

b. Berdasarkan nilai dari kontribusi derajat kecanggihan komponen teknologi Kapal MM dihadapkan dengan kondisi ideal (bernilai 1), maka gap tertinggi adalah pada komponen technoware sebesar 0,67, tertinggi kedua humanware sebesar 0,43, tertinggi ketiga infoware sebesar 0,41, dan terakhir adalah orgaware sebesar 0,36.

c. Berdasarkan hasil pengukuran TCC menunjukkan Kapal MM memiliki nilai 0,48, sehingga masuk dalam klasifikasi teknologi semi modern dengan kategori cukup.

d. Berdasarkan gap pada komponen teknologi, maka yang menjadi prioritas pengembangan komponen teknologi adalah yang memiliki nilai gap tertinggi yaitu technoware.

\section{Rekomendasi}

Pada penelitian ini terdapat beberapa rekomendasi yang terdiri dari praktis dan teoritis sebagai berikut :

\section{Praktis}

a. Perlunya diadakan peninjauan ulang terhadap peralatan-peralatan yang digunakan di KRI Kelas Mandau, mengingat nilai kontribusi individual technoware rendah.

b. Perlunya dilaksanakan penyesuaian terkait komponen technoware yang ada saat ini, dengan mengambil referensi kapal yang telah menggunakan technoware yang modern.

c. Agar memprioritaskan komponen technoware dalam pengembangan komponen teknologi di Kapal MM. 


\section{Teoritis}

Penelitian ini bukanlah merupakan hasil akhir melainkan awal dari penelitian-penelitian selanjutnya mengenai manajemen teknologi, terutama di kapal perang. Agar hasil penelitian lebih sempurna, maka diberikan rekomendasi sebagai berikut :

a. Agar pada penelitian-penelitian berikutnya, misalnya dalam mengkaji efektivitas penggunaan MCDM lain seperti ANP, FUZZY-AHP ELECTRE, PROMETHEE atau mengembangkan metoda teknometriks yang memungkinkan mengukur kapabilitas teknologi, sehingga proses pemilihan dan pengelolaan teknologi bisa lebih mudah dilakukan.

b. Agar dalam menentukan kriteri dan sub-kriteria dari masing-masing komponen teknologi di kapal perang lebih detail lagi, misalnya untuk humanware melibatkan seluruh personel kapal mulai dari komandan sampai dengan personel pangkat terendah sesuai tugasnya.

\section{DAFTAR PUSTAKA}

Ahmad S. (2014). Technology in Organizations. Int J. Res. Bus. Manag. 2:2321-886

Anis Y, Listiyono H, Khristianto T. 2015. Analytic Hierarchy Process ( AHP ) Sebagai Alat Untuk Pengambilan Keputusan Seleksi Pemasok Obat-Obatan. Din. Inform. 7:10.

Bennett D, Vaidya K. 2011. Meeting technology needs of enterprises for national competitiveness. Int. J. Technol. Manag. 32:112-153. doi:10.1504/IJTM.2005.006821.

Cahyono DECW. 2015. Penilaian Teknologi Mengunakan Analytical Hierarchy Process dan Teknometrik di Departemen Produksi. :122129.

Coccia M. 2018. Scientific Data of some Functional Measures of Technology: Farm Tractor (mechanical efficiency), Freight Locomotive (tractive effort in pound) and Passenger Aircraft (airspeed in miles per hour), Mendeley Data, v1. Available at: http://dx.doi. org/10.17632/kjbdzy7v8j.1 (Embargo Date: 2019-02-14)

Daim, T.U., Byung-Sun, Y., Lindenberg, J., Grizzi, R., Estep, J., \& Oliver, T. (2018). Strategic roadmapping of robotics technologies for the power industry: A multicriteria technology assessment, Technological Forecasting \& Social Change, 131, 49-66. doi. 10.1016/j. techfore.2017.06.006.

Darmanto E. 2014. Penerapan Metode AHP ( Analythic Hierarchy Process ) Untuk Menentukan Kualitas Gula Tumbu. J. SIMETRIS 5:75-82.

Foden J, Berends H. 2010. Technology Management at Rolls-Royce. Res. Manag. 53:33-42. doi:10.1080/08956308.2010.11657619.

Gudanowska AE. (2017). A Map of Current Research Trends within Technology Management in the Light of Selected Literature. Manag. Prod. Eng. Rev. 8:78-88. doi:10.1515/ mper-2017-0009.
Hamid S-R, Chew B-C, Halim S. 2012. What's the Principles of Technology Management-Eliciting Technology ManagementPrinciples through Expert Opinion. Int. J. Innov. Manag. Technol. 3:631-636. doi:10.7763/IJIMT.2012. V3.310.

Indriartiningtias R, Amijaya R, Nugroho W. (2014). Penilaian Teknologi Untuk Menentukan Posisi Teknologi 2 Industri Skop Dengan Metode Teknometrik. Prosiding Seminar Internasional Manajemen Teknologi, MMT-ITS. Surabaya.

Irianto, B.G., Rahman, A., Andayani, D.H. (2015). Technology Content Analysis with Technometric Theory Approach to Improve Performance in Radiodiagnostic Installation. Journal of Electrical Engineering Vol. 14, No. 2, pp. 353- 362. http://DOI: 10.11591/telkomnika.v14i2.767.

Killic, B. (2019). Stress Among ab-initio Pilots : A model of contributing factors by AHP. Journal of Air Transport Management, Volume 80. https: //doi.org /10.1016/ j.jairtraman. 2019.101706.

Lungari, F.F., Manfaat, D., Ma'ruf, B. (2016). Pengukuran Tingkat Kesiapan Komponen Teknologi Di Galangan Kapal Kelas Menengah Berdasarkan Metode Teknometrik (Studi Kasus: PT. Dumas Tanjung Perak Shipyard). Jurnal Wave Volume 10 Nomor 2, hal: 53-60.

Nazaruddin. 2008. Manajemen Teknologi. Pertama. Yogyakarta: Graha Ilmu.

Pujianto, T., Hasbullah, R.A., Ardiansah, I. (2017). Penilaian Kontribusi Komponen Teknologi dalam Aktivitas Produksi di PT Z Menggunakan Metode Teknometrik. Jurnal Teknologi dan Manajemen Agroindustri, Volume 6 No 3: 133-14. https://doi.org/10.21776/ ub.industria.2017.006.03.4.

Saaty TL. 2008. Decision making with the analytic hierarchy process. Int. J. Serv. 46 Sci. 1:83. doi: 10.1504/IJSSCI.2008.017590.

Setiawan, J.,Tontowi, A.E., Sri Asih, A.M. (2015). Kesiapan Teknologi, Kelayakan Ekonomi Dan Administrasi Ikm Mainan Di Yogyakarta. Jurnal Dinamika Kerajinan dan Batik, Vol. 32, No. 2.

Susihono, W. (2012). Penilaian Teknologi Untuk Menentukan Posisi Industri Pesaing. Jurnal Teknik Industri Undip, Vol VII, No 2.

Undang-Undang RI No. 34 tahun 2004, tentang Tentara Nasional Indonesia.

Virliantarto, N., Buana Ma'ruf, B., Suastika, K. (2017). Pengukuran Kesiapan Teknologi Untuk Pembangunan Kapal Kontainer 100 Teus Dengan Sistem Modular Di PT. Pal Indonesia. Jurnal Wave Volume 11 Nomor 1, Hal: 31-38.

Wang, C.C., Sung, H.Y., \& Huang, M.H. (2016). Technological evolution seen from the USPC reclassifications, Scientometrics , 107(2), 537-553. doi. 10.1007/s11192-016-1851-3.

YANTHI, E.R. (2018). Analisis Kontribusi Komponen Teknologi (Technoware, Humanware, Infoware, Orgaware) Pada Perusahaan Jasa Transportasi Kereta Api Barang Dengan Pendekatan Model Teknometrik. Bogor, INA : Institut Pertanian Bogor. 